\title{
Risk Assessment of Chestnut Drought Disaster in Qixian County
}

\author{
Chen xiaojuan ${ }^{1,2}$ Liting $^{1}$ Weijun ${ }^{1,2}$ Zhangjing ${ }^{1}$ \\ 1. Hebei Meteorological Disaster Prevention Center;2. Key Laboratory of Meteorology and Ecological \\ Environment of Hebei Province \\ Shijiazhuang, China \\ juan2044335@163.com \\ 迁西县板栗干旱灾害风险评估 \\ 陈笑娟 ${ }^{1,2}$ 李婷 ${ }^{1}$ 张静 ${ }^{1}$ 魏军 ${ }^{1,2}$ \\ 1. 河北省气象灾害防御中心 \\ 2.河北省气象与生态环境重点实验室 \\ 石家庄 050021, 中国 \\ juan2044335@163.com
}

\begin{abstract}
Based on daily precipitation of Qianxi and six surrounding counties from 1984 to 2015, we estimate the risk of drought in Qianxi county during a series of return periods by probability distribution. So does the chestnut-drought risk by distribution of chestnut and relative risk grade. It is concluded that the risk of drought is higher in the southwest of Qianxi. The drought area and intensity increase with the augment of return period. Percentage of precipitation departure is $-43 \%$ in Baimiaozi, Xingcheng, Xinzhuangzi and Donglianhua township when the return period is $30 a$. It is $\mathbf{- 5 2 \%}$ when the return period being 100a. The distributions of chestnuts are largest in Yangjiayu and Shimenzi village, Hanerzhuang township, which are 683 and 670 ha. Influenced by hazard factor and bearing body, the risk grade is highest in most areas of Hanerzhuang, Luanyang, Shangying and Jinchangyu town.
\end{abstract}

Keywords-chestnut; drought; risk; risk grade 摘要一本文基于 1984-2015 年的迁西县及周围 6 个县的日 降水量资料, 运用概率分布理论对不同重现期下迁西干旱致 灾因子危险性进行评估, 并结合各村板栗暴露数据, 利用相 对风险等级法, 对板栗干旱进行风险评估。结果表明: 迁西 县西南部干旱致灾因子危险性相对较高。随着重现期的增 大, 干旱面积和致灾强度也在增加, 白庙子乡、兴城镇、新 庄子乡和东莲花院乡 30 年一遇的降水距平百分率达 $-43 \%$, 100 年一遇达 $-52 \%$ 。汉儿庄乡的杨家峪村、石门子村的板栗种 植面积最多, 分别为 683 和 670 公顷。风险受到致灾因子与 承灾体共同作用，北部的汉儿庄、㴒阳、酒河桥、上营和金 厂峪乡镇大部地区的风险等级较高。

关键词一板栗, 干旱, 风险, 风险等级

\section{I. 引言}

干旱是影响河北省的主要气象灾害之一, 会造成水 文学不平衡, 对土地资源生产系统造成严重影响 ${ }^{[1]}$ 。近 年来在全球气候变化背景下, 出现年平均气温升高、降 水量减少的现象，致使暴露于自然下的农业生产是受到 干旱影响, 因旱灾造成的损失逐年加剧[2]。据《河北经 济年鉴》 ${ }^{[3]}$ 及《中国统计年鉴》 ${ }^{[4]}$, 在1984 2015年32年 间, 河北省干旱灾害频发, 成灾面积在 100 万 $\mathrm{hm}^{2}$ 以上的
年份有12个，其中1989、1992、1997、1999和2000年早 灾灾情尤为严重, 成灾面积均超过 200 万 $\mathrm{hm}^{2}$ 。迁西板栗 作为河北省传统特色农产品, 全县栽植面积 75 万亩, 5000 万株，常年产量 8 万吨，板栗产业成为全县农民增 收致富的最主要渠道。生长期内干旱灾害会对板栗的光 合强度、叶片以及单株产量造成不利影响[5], 尤其果实 膨大期对水分较为敏感，因此开展板栗干旱灾害的风险 评估研究, 对于农业气象灾害风险管理, 减少损失, 稳 定生产具有重要的现实意义。

根据灾害系统理论, 旱灾风险主要取决于干旱致灾 因子的危险性、承灾体的暴露性和脆弱性。因此, 本研 究从以上三方面入手，运用概率分布理论对不同重现期 下迁西市干旱致灾因子危险性、承灾体脆弱性和风险进 行评估, 以期为指导生产和防灾减灾决策提供理论依 据。

\section{II. 资料来源及研究区概况}

致灾因子数据为 1984-2016 年河北省迁西市及其相 邻六个县域 (兴隆、宽城、青龙、遵化、迁安、丰润) 的国家站与区域站的日降水数据计算得到的降水距平百 分率，来自河北省气象局; 承灾体数据为 2016 年迁西 市各村的板栗种植面积和产量数据, 来自迁西市气象 局; 地理信息数据包括行政区划矢量 SHP 数据和分辨率 为 $25 \mathrm{~m}$ 的高程 DEM 数据, 来自河北省地理信息局。 迁西是闻名世界的中国板栗之乡，位于北纬 $39^{\circ} 57^{\prime} 15^{\prime \prime} 40^{\circ} 27^{\prime} 48^{\prime \prime}$, 东经 $118^{\circ} 06^{\prime} 49^{\prime \prime}-118^{\circ} 37^{\prime} 19^{\prime \prime}$, 地处 河北省东北部, 燕山沉降带东段南缘, 全县地势为四周 高、中间低、向中间倾斜，呈低山丘陵地貌（图 1）, 北与宽城相望，西与兴隆、遵化接壤，南与丰润相连， 东与迁安、青龙为邻。县域面积 1439 平方公里, 呈“七 山一水分半田, 海拔最高达 $821.3 \mathrm{~m}$, 最低为 $65.5 \mathrm{~m}$, 相 对高度差 $755.8 \mathrm{~m}$ 。迁西县属东部季风区暖温带半湿润气 候，四季分明，春、夏、秋、冬季的降雨量分别占全年 的 $9.3 \% 、 75.2 \% 、 13.8 \% 、 1.7 \% ，$ 降水分配不均匀，易 
形成旱涝灾害。 2012 年和 2015 年 8 月, 迁西降水量分 别为 $53.6 \mathrm{~mm}$ 和 $68.4 \mathrm{~mm}$, 仅是常年降水量的 $30 \% \sim 40 \%$, 该两年板栗减产 $40 \% \sim 50 \%{ }^{[6]}$ 。

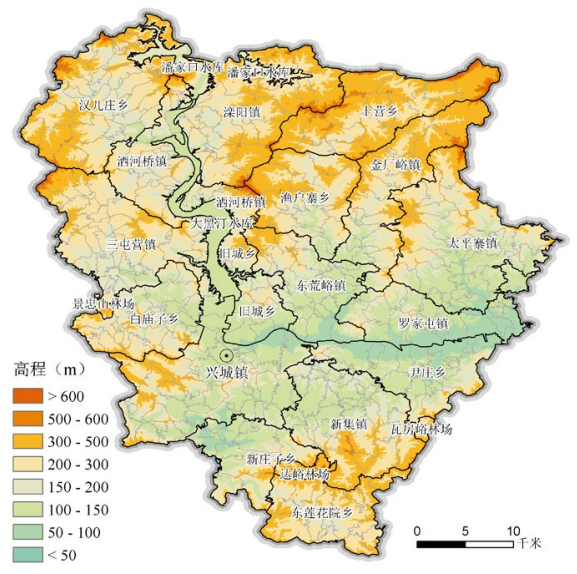

图 1 迁西县地势

\section{III. 研究方法}

\section{1. 致灾因子危险性}

选取板栗生育期内的降水距平百分率作为干旱灾 害致灾强度评价指标。降水距平百分率表征某一具体时 段内的降水量较常年同时段平均水平偏多或者偏少的程

度, 能够直观反应由降水异常引起的干旱[7]。根据

《GB/T 20481-2017 气象干旱等级》 [8], 降水距平百分率

$$
\begin{aligned}
& \left(P_{a}\right) \text { 计算公式为: } \\
P_{a}= & \frac{P-\bar{P}}{\bar{P}} \times 100 \%
\end{aligned}
$$

式中, $P_{a}$ 为板栗生育期内的降水距平百分率 $(\%), \mathrm{P}$ 为该时段内的降水量 $(\mathrm{mm}), \bar{P}$ 为同期的多年平均降 水量 $(\mathrm{mm})$, 至少为 30 年均值。

重现期是一种能够反映极端事件发生强度与概率的 重要指标, 在气候概率统计学上, 根据历史实测资料的 分布来推算极端事件在长时间序列中发生的概率, 对于

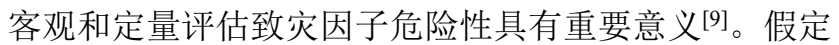
$X$ 为连续型随机变量, 对于任意实数 $x$ 来说, $X<x$ 的概 率为:

$$
F(X)=P(X<x)=\int_{-\infty}^{x} f(x) \mathrm{d} x
$$

式中, $X$ 为气候要素的极值变量, $F(X)$ 为其累计概 率分布, $x$ 为某一取值, $f(x)$ 为其概率密度函数。超过 $x$ 应取概率密度函数的右侧概率, 而对于干旱灾害而言,

应取左侧概率, 对于重现期 $T$, 则有 $T=\frac{1}{F(X)}$ 。

根据计算得到的降水距平百分率构建年数据序列, 进行分布函数拟合，通过科尔莫洛夫一斯米尔诺夫

(Kolmogorov-Smirno, KS) 检验拟合优度, 确定各站
点的最优分布函数 ${ }^{[10],}$ 然后计算不同重现期致灾强度, 通过 GIS 手段绘制致灾因子危险性空间分布。

2.承灾体脆弱性

对于板栗承灾体选取其暴露度表征脆弱性，承灾体 物理暴露性是指暴露在自然灾害致灾因子影响范围内的 承灾体数量或价值量, 它是界定自然灾害风险存在与否 的必要条件之一，与其自身的总量密切相关，反映了在 一定强度致灾因子的影响下可能遭受的损失数量。暴露 度分析体现了承灾体的分布和强度的信息。因此，对于 自然灾害风险而言, 暴露量越大, 灾害风险也就越大。

3. 承灾体损失风险

根据式（3）风险评估模型和风险矩阵法对板栗干 旱灾害进行风险评估:

$$
R(t)=H(t) \times V
$$

式中, $R(t)$ 为 $t$ 年一遇干旱灾害风险, $H(t)$ 为致灾因 子危险性, $V$ 为承灾体脆弱性。

风险矩阵法是识别风险重要性的一种结构性方法

（图 2），根据风险矩阵原理，将致灾因子危险性按照 自然断点法分成极低, 低, 中, 高, 极高五类并赋值为 $1-5$, 承灾体脆弱性按照分位数法分成极低, 低, 中, 高, 极高五类并赋值为 1-5。根据式（3）将计算得到的 风险值分为五类：极低风险(1-5), 低风险(5-10), 中等

风险(10-15), 高风险(15-20), 极高风险(20-25)。

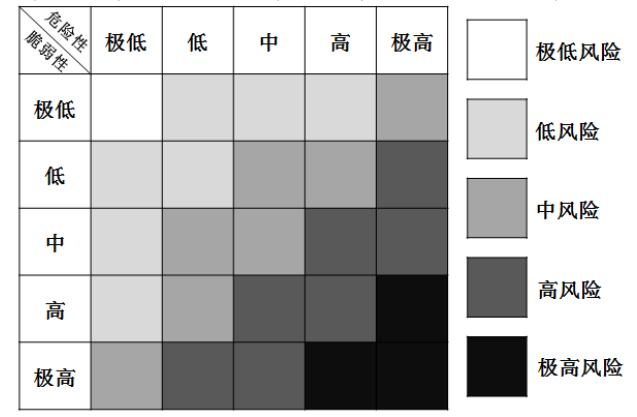

图 2 风险矩阵图

IV. 结果与分析

1.致灾因子危险性评估

图 3 为迁西县干旱灾害致灾因子危险性分布。可 以看出, 重现期为 5、10、30 年一遇时, 迁西县北部边 缘地区旱灾致灾危险性较低, 其他地区的降水距平百分 率差异不大, 差值在 2\%以内。随着重现期的增大, 干 旱致灾强度在增加, 5、10、30 年一遇的降水距平最小 值依次为 $-23 \% 、-32 \%$ 和 $-43 \%$ 。 50 年和 100 年一遇时, 高值区向西偏移, 迁西县西南部的旱灾危险性明显高于 其他地区, 并且在白庙子乡、兴城镇、新庄子乡和东莲 花院乡 50 年一遇的降水距平百分率达 $-47 \%, 100$ 年一遇 的降水距平百分率达 $-52 \%$ 。 

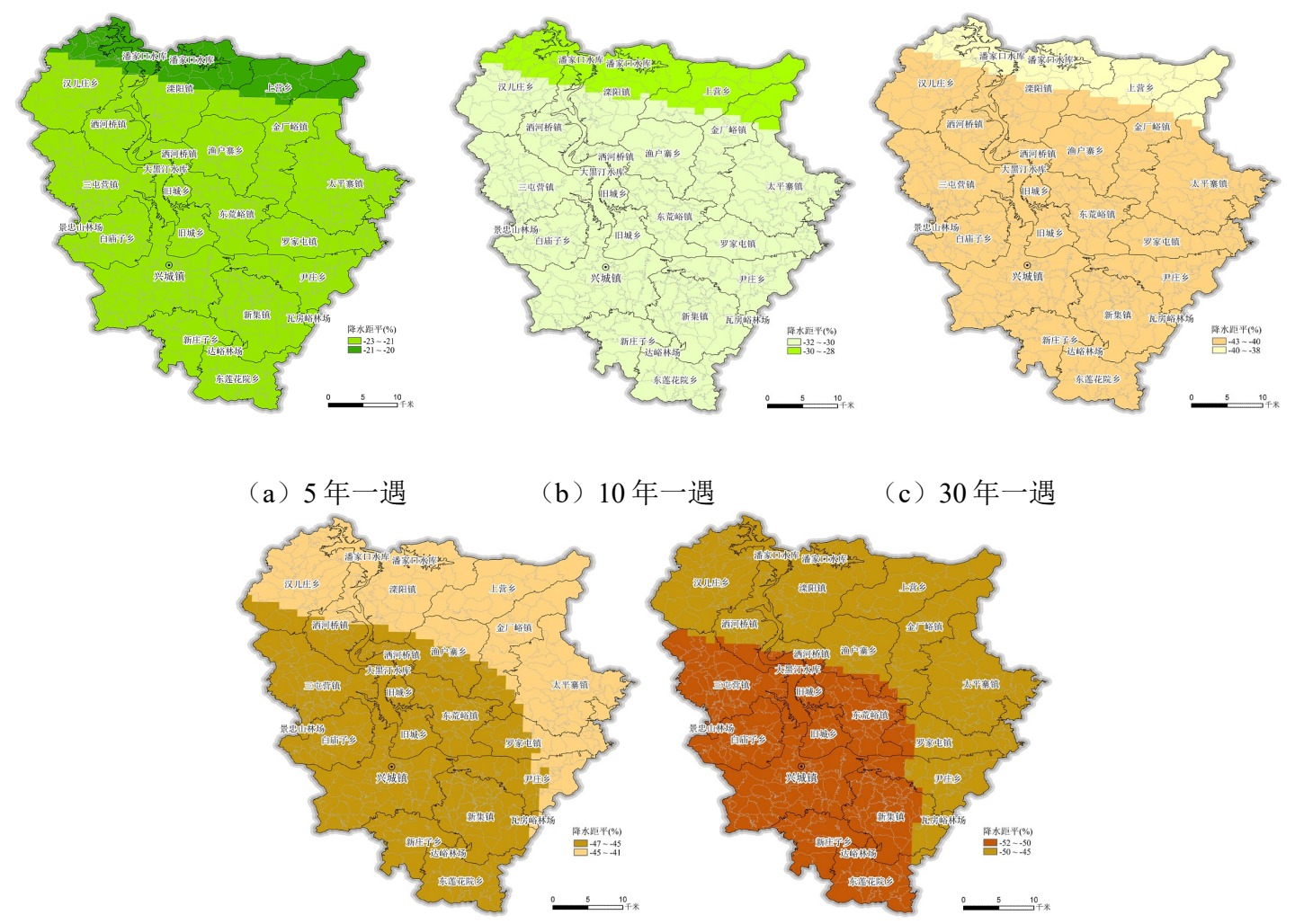

(d) 50 年一遇

(e) 100 年一遇

2 承灾体脆弱性评估

图 4 为迁西县板栗的种植面积分布。各村种植面积 从 0 到 683 公顷分布不均, 从总体上看, 呈现北部高于 南部的分布特征, 密集区位于地势相对较高的北部。北 部的汉儿庄乡、滦阳镇、酒河桥镇、上营乡和金厂峪镇 的种植面积较大, 产量较高, 其中汉儿庄乡的杨家峪 村、石门子村种植面积最多, 分别达 683 公顷、670 公 顷, 而在兴城镇和新集镇的部分村庄没有种植板栗。

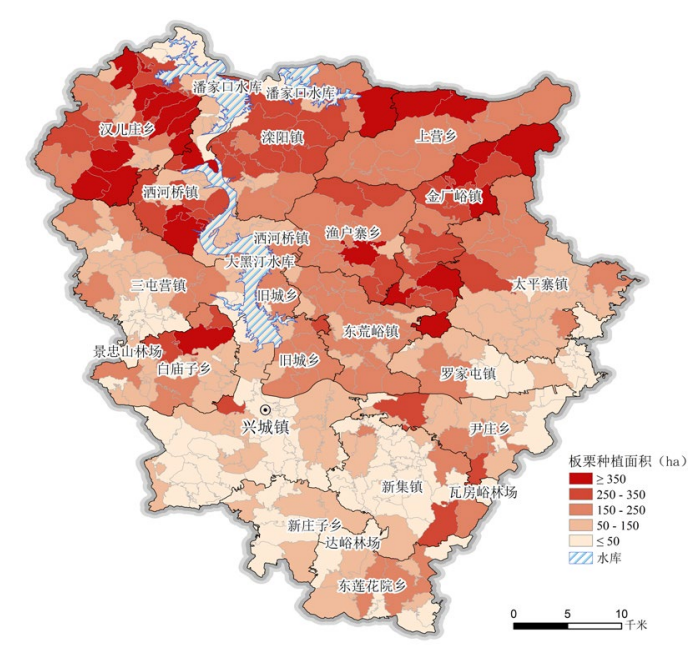

图 4 迁西县板栗种植面积

3. 承灾体损失风险评估

风险是致灾因子与承灾体综合作用的结果。图 5 为不同重现期迁西县板栗干旱灾害的损失风险分布情 况。可以看出，相对风险的分布总体上与承灾体的空间 分布较为一致, 即北部地区的风险高于南部地区, 其
中, 北部的汉儿庄、㴒阳、酒河桥、上营和金厂峪乡镇 大部地区的风险等级较高。重现期为 5 年一遇时, 全县 处于低风险和极低风险, 10 年一遇时, 迁西北部呈现出 中高风险, 30、50、100 年一遇时, 并且随着重现期的 增加, 风险等级越高, 高风险的范围越大, 北部呈现极 高风险等级。因此, 在板栗种植管理时, 将干旱风险等 级较高的北部五个乡镇应重点采取防灾减灾措施, 如浇 灌、人工增雨等, 并优先参加相关农业保险, 以分散转 移和降低风险。

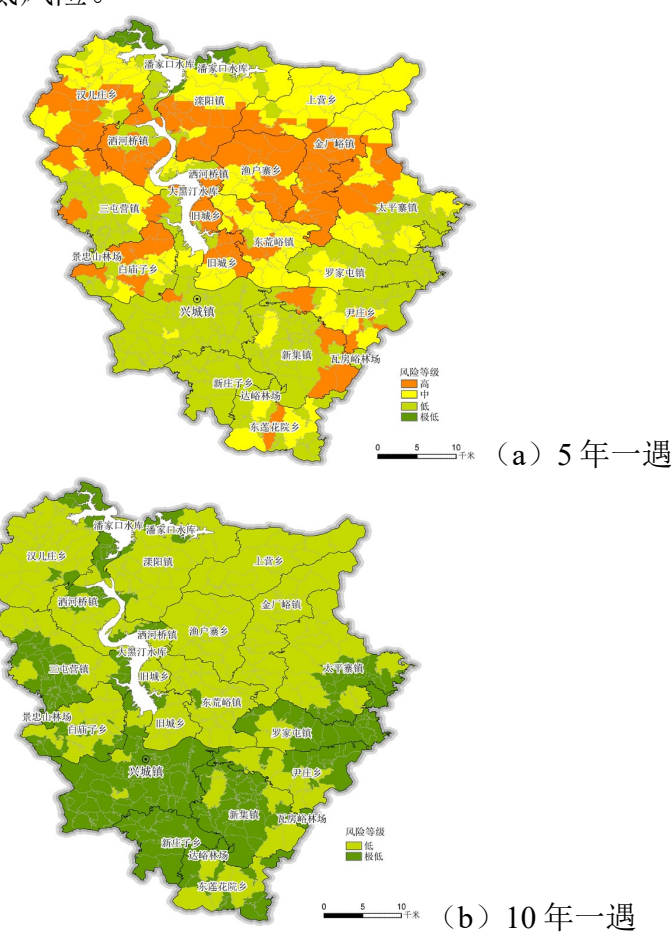




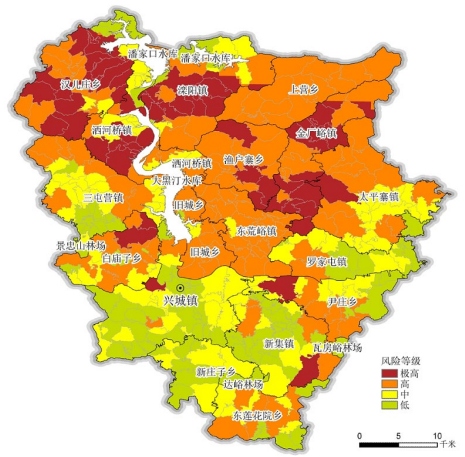

(c) 30 年一遇

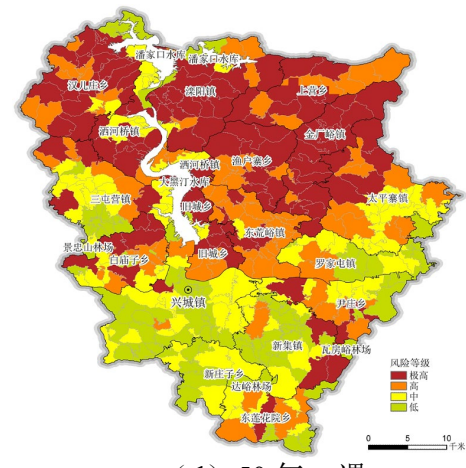

（d） 50 年一遇

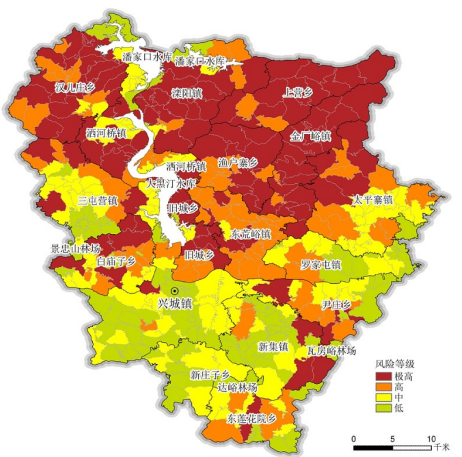

(e) 100 年一遇

图 5 迁西县干旱灾害板栗风险评估

\section{V. 结论与讨论}

利用 1984-2016 年的迁西县及相邻 6 个县的日降水 量资料，基于概率分布理论对不同重现期下迁西县板栗 干旱灾害进行风险评估，主要结论如下：

（1）随着重现期的增大，干旱致灾强度和范围在增 加, 西南部旱灾危险性较高, 30 年一遇的降水距平百分 率达 $-43 \%, 100$ 年一遇的降水距平百分率达 $-52 \%$ 。这与 前人研究一致 ${ }^{[11]}$ 。

（2）板栗的村种植密集区位于地势相对较高的北部, 汉儿庄、㴒阳、酒河桥、上营和金厂峪乡镇产量较高, 其中杨家峪村、石门子村种植面积多达 683 公顷和 670 公顷。

（3）相对风险的分布与承灾体的空间分布较为一致, 北部高于南部，在北部的汉儿庄、㴒阳、洒河桥、上营 和金厂峪乡镇大部地区的风险较高, 且随着重现期的增 加, 风险等级越高, 高风险的范围越大。

(4) 在板栗种植管理时, 将干旱风险等级较高的北部 五个乡镇应重点采取防灾减灾措施, 如浇灌、人工增雨 等; 并优先参加相关农业保险, 以分散转移和降低风 险。

干旱灾害是迁西县主要气象灾害，本研究受气象灾 情资料所限, 利用相对风险等级法进行了板栗干旱灾害 评估, 如后期能获得较完备的板栗干旱灾情资料，制作
灾害曲线, 可以做到定量风险评估, 将为板栗干旱灾害 风险预警服务提供更精细化的决策依据。

\section{致谢}

本项目受 2018 年河北省气象局业务建设项目 “县级 气象灾害风险普查及区划编制”资助。

\section{参考文献}

[1] 陈颙, 史培军. 自然灾害(修订版). 北京: 北京师范大学出版 社, 2007, pp.29-42.

[2] 商彦荵. 河北省农业旱灾脆弱性区划与减灾. 灾害学, vol.16, issue 3, pp.28-32, 2001 .

[3] 河北省统计局. 经济年鉴, http://www.hetj.gov.cn/hetj/tjsj/jjnj/, 2016-12-01.

[4] 中华人民共和国国家统计局.中国统计年鉴, http://www.stats.gov.cn/tjsj/ndsj/, 2016-12-01.

[5] 张继亮, 孙海伟, 马玉敏. 生长前期干旱对板栗生长结果的影响. 落 叶果树, issue5,pp. 8-9, 2000.

[6] 高桂芹, 王猛, 费晓臣, 等. 迁西县板栗气象干旱指数保险产品设计. 现代农业科技, issue 2, pp. 182-185, 2017.

[7] 王富强, 王雷. 基于降水距平百分率的河南省干旱特征分析. 中国 农村水利水电, issue 12, pp. 84-88, 2014.

[8] 中国气象局. GB/T 20481-2017 气象干旱等级. 2017.

[9] 李美荣, 李星敏, 柏秦风, 等, 苹果极端气象灾害气温极值的分布及 重现期预测. 干旱地区农业研究, vol.16, issue 3, pp.257-261, 2012.

[10] 丁裕国, 江志红. 极端气候研究方法导论. 北京: 气象出版社, 2009.

[11] 李婷, 孙玉龙, 陈笑娟, 等. 基于经济损失的河北省雪灾风险定 量评估。灾害学, vol.33, issue 4, pp. 72-76, 2018.. 